\title{
KOMPARASI KEANEKARAGAMAN ARTHROPODA PERMUKAAN TANAH PADA KOMODITAS CABAI MERAH, CABAI RAWIT DAN TOMAT
}

(Comparison of soil surface arthropod diversity on commodities of red chilies, bird's eye chilies and tomatoes)

\author{
Jasridah, Alfian Rusdy, Hasnah Hasnah* \\ ${ }^{1}$ Program Studi Proteksi Tanaman, Fakultas Pertanian, Universitas Syiah Kuala \\ *Corresponding author: email: hasnah@unsyiah.ac.id
}

\begin{abstract}
Abstrak. Pola tanam monokultur merupakan sistem budidaya tanaman pada suatu areal lahan yang ditanami dengan satu jenis tanaman saja. Pertanaman monokultur dapat memicu eksplosif hama tertentu, karena sistem budidaya ini dapat menyebabkan agroekosistem menjadi tidak stabil. Beberapa faktor penyebab terjadinya kerentanan agroekosistem terhadap peledakan hama adalah penurunan keragaman lanskap, penurunan keragaman tanaman, penggunaan pestisida, pemupukan yang tidak berimbang dan faktor iklim. Perangkap yang digunakan dalam penelitian ini adalah pitfall trap. Peubah yang diamati meliputi populasi arthropoda permukaan tanah, indeks keanekaragaman dan indeks kelimpahan. Pada pertanaman cabai merah terdapat 8 ordo Arthropoda permukaan tanah dengan total 546 individu. Pada cabai rawit terdapat 9 ordo dengan total 599 individu, sedangkan pada tanaman tomat terdapat 11 ordo dengan total 399 individu. Ordo Hymenoptera dari famili Formicidae terdapat pada ketiga komoditi ditemukan 598 individu, sedangkan ordo yang paling sedikit ditemukan pada ordo Blattodea 1 individu. Nilai indeks keanekaragaman pada ketiga tanaman berkisaran $(1,27-1,64)$, indeks kelimpahan pada ketiga tanaman berkisaran $(0,23-0,38)$.
\end{abstract}

Kata Kunci: Biodiversitas, Arthropoda permukaan tanah, Solanaceae, Monokultur.

Abstract. Monoculture cropping pattern is a system of plant cultivation in an area of land that is planted with only one type of plant. Monoculture cropping can trigger the explosion of certain pests, because this cultivation system can cause the agro-ecosystem to become unstable. Several factors causing the vulnerability of agroecosystems to pest explosions are the decrease in landscape diversity, the decrease in plant diversity, the use of pesticides, unbalanced fertilization and climatic factors. The trap used in this research is the pitfall trap. The observed variables included ground surface arthropod population, diversity index and abundance index. In red chili plantations, there are 8 orders of arthropods on the ground with a total of 546 individuals. In cayenne pepper there are 9 orders with a total of 599 individuals, while in tomato plants there are 11 orders with a total of 399 individuals. The order Hymenoptera of the Formicidae family was found in all three commodities, found 598 individuals, while the least order was found in the order Blattodea 1 individual. The value of the diversity index in the three plants ranged (1.27-1.64), the abundance index of the three plants ranged (0.23-0.38).

Keywords: Biodiversity, Ground surface arthropods, Solanaceae, Monoculture.

\section{PENDAHULUAN}

\section{Latar Belakang}

Budidaya tanaman sayuran di Indonesia umumnya dilakukan dengan menggunakan pola tanam secara monokultur dan polikultur. Pola tanam monokultur merupakan sistem budidaya tanaman pada suatu areal lahan yang ditanami dengan satu jenis tanaman saja. 
Pertanaman monokultur dapat memicu eksplosif hama tertentu, karena sistem budidaya ini dapat menyebabkan agroekosistem menjadi tidak stabil. Beberapa faktor penyebab terjadinya kerentanan agroekosistem terhadap peledakan hama adalah penurunan keragaman lanskap, penurunan keragaman tanaman, penggunaan pestisida, pemupukan yang tidak berimbang dan faktor iklim (Nurindah, 2006). Sistem tanam monokultur mampu meningkatkan organisme serangga hama dan menjadikan ekosistem pertanian yang rentan. Pendorong salah satu peningkatan serangga hama yaitu banyaknya kesediaan makanan yang terus menerus sepanjang waktu dan disetiap tempat. Intensifikasi pertanaman mempunyai suatu penyederhanaan terhadap sistem pertanian. Fungsi dari agen pengendalian hayati atau musuh alami akan berpengaruh terhadap penggunaan penyederhanaan terhadap sistem pertanaman dan pengurangan dari biodiversitas. Apabila habitat musuh alami semula memiliki biodiversitas yang tinggi menjadi habitat baru maka musuh alami akan mengalami perubahan atau penyesuaian (Bianchi et al., 2006).

Pola pertanaman dalam suatu agroekosistem berpengaruh terhadap keanekaragaman fauna, salah satunya adalah arthropoda. Keberadaan fauna tanah sangat dipengaruhi oleh faktor lingkungan yaitu faktor abiotik dan faktor biotik. Faktor lingkungan abiotik yang sangat mempengaruhi yaitu meliputi tekstur tanah, struktur tanah, $\mathrm{pH}$, salinitas, kadar bahan organik dan unsur mineral tanah. Faktor biotik yang mempengaruhi antara lain makrofauna dan mikrofauna, yang berperan baik sebagai dekomposer, predator, fitofag dan parasitoid (Sembiring, 2020). Selanjutnya Agustinawati et al. (2016) menyatakan bahwa, arthropoda permukaan tanah memiliki peran penting dalam pengaturan hayati, kimiawi serta fisik dari ekosistem tanah atau juga disebut dekomposer serta sebagai makhluk penyeimbang dalam lingkungan.

Keanekaragaman spesies dalam suatu daerah maupun kawasan sangat dipengaruhi oleh faktor di antaranya sumber pakan, musim, iklim dan tipe habitat. Sumber pakan yang melimpah akan meningkatkan keanekaragaman spesies menjadi lebih tinggi dan dapat dijadikan sebagai tempat hidup dibandingkan daerah yang sumber pakannya yang kurang. Musim dan iklim juga menyebabkan perbedaan tinggi rendahnya keanekaragaman spesies di suatu daerah. Biasanya pada musim penghujan suatu spesies akan meningkat karena banyaknya tersedia sumber makanan dibandingkan dengan musim kemarau. Selain itu, tipe vegetasi seperti keadaan tanah dan keanekaragaman serasah dapat mempengaruhi jumlah arthropoda yang ditemukan pada habitat tersebut (Normasari, 2012).

Arthropoda permukaan tanah merupakan arthropoda tanah yang beraktivitas dan keberadaannya di atas permukaan tanah. Arthropoda permukaan tanah dalam suatu agroekosistem dapat berperan sebagai predator contohnya famili Carabidae, Staphylinidae, Formicidae, Lycosidae dan Thomisidae. Selanjutnya yang berperan sebagai herbivora antara lain famili Gryllidae dan Gryllotalpidae, yang berperan sebagai detrivor antara lain famili Ectobiidae, Trigoliunidae dan Scarabaeidae, dekomposer antara lain famili Paradoxosomatidae, Termitinae dan Entomobrydae (Qiptiyah, 2014).

Latoantja et al. (2013) menyatakan bahwa kelimpahan arthropoda permukaan tanah pada pertanaman cabai pada 20 hari setelah tanam yaitu sebanyak 290 individu yang terdiri dari 6 ordo dan 11 famili Salticidae, Oxyopidae, Gryllidae, Acrididae, Formicidae, Dryinidae, Eulophidae, Coccinelidae, Pyrrhocoridae, Syrphidae dan Dolicophodidae. Arthropoda permukaan tanah yang ditemukan pada areal pertanaman cabai rawit di Desa Kuripan Kecamatan Kuripan Kabupaten Lombok Barat NTB selama 10 kali pengamatan adalah 240 individu yang terdiri dari 7 famili diantaranya yaitu Lycosidae, Oxyopidae, Araneidae, Acrididae, Carabidae, Formicidae dan Trigoniulidae (Yasurruni et al., 2018).

Hasil penelitian Arifta (2016) menunjukkan bahwa keanekaragaman arthropoda tanah ditemukan pada area pertanaman tomat sebanyak 19 famili dan 21 genus di antaranya adalah 
genus Scolopendra, Paederus, Lycosa, Blattelidae, Folsomidae, Platydema, Entomobrya, Gryllus, Actractomorpha dan Desineura. Selanjutnya Al-daikh et al. (2018) menambahkan bahwa, tingkat keanekaragaman arthropoda tanah di area lahan pertanaman tomat organik ditemukan sebanyak 21 ordo diantaranya adalah Diptera, Hymenoptera, Homoptera, Hemiptera, Neuroptera, Collembola, Coleoptera, Lepidoptera, Thysanoptera, Orthoptera, Ephemiptera, Dermaptera, Prostigmata, Astigmata, Cryptostigmata, Notostigmata, Mesostegmata, Teterastigmata, Chilophoda, Crustacea dan Spiders.

Berdasarkan uraian di atas merupakan langkah awal dalam upaya menerapkan pola pengelolaan hama secara terpadu dan berwawasan lingkungan dalam suatu agroekosistem.

\section{METODE PENELITIAN}

\section{Tempat dan Waktu Penelitian}

Penelitian ini dilaksanakan di Gampong Kuta Malaka Kecamatan Indrapuri Kabupaten Aceh Besar, dan di Laboratorium Hama Tumbuhan Program Studi Proteksi Tanaman Fakultas Pertanian Universitas Syiah Kuala. Penelitian ini dilaksanakan mulai dari bulan Maret sampai Juni 2020.

\section{Prosedur Penelitian}

\section{Pola penanaman}

Pada areal persawahan ditanam 3 jenis tanaman, yaitu cabai merah, cabai rawit dan tomat dengan ukuran bedeng $12 \mathrm{~m}$ dan lebar $1 \mathrm{~m}$ dengan ketinggian bedeng $30 \mathrm{~cm}$. Total bedeng yang digunakan adalah sebanyak 30 bedeng, dengan jarak antar bedeng $40 \mathrm{~cm}$ serta jarak tanaman $30 \mathrm{~cm}$, sehingga diperoleh 40 tanaman perbedeng. Jumlah bedengan untuk masing-masing jenis tanaman adalah 10 bedeng.

\section{Pembuatan perangkap}

Pitfall trap merupakan salah satu perangkap untuk mengetahui kelimpahan arthropoda permukaan tanah. Perangkap ini terbuat dari wadah aqua gelas dengan tinggi $9 \mathrm{~cm}$, diameter bagian atas $70 \mathrm{~mm}$, sedangkan diamater bagian bawah $40 \mathrm{~mm}$. Wadah aqua gelas tersebut ditanam di tanah dengan posisi lebih ditinggikan dari permukaan tanah agar air yang mengalir dipermukaan tanah tidak masuk kedalam perangkap. Selanjutnya aqua gelas plastik diisi dengan larutan zat perangkap sebanyak $100 \mathrm{ml}$ (air $100 \mathrm{ml}+$ deterjen $4 \mathrm{gr}+$ garam $4 \mathrm{gr}$ ) kemudian ditutup dengan seng (panjang dan lebar sama yaitu $30 \mathrm{~cm} \times 25 \mathrm{~cm}$ ) yang berbentuk seperti atap rumah untuk menghindari air masuk kedalam perangkap.

\section{Teknik pemasangan perangkap}

Pemasangan pitfall trap dilakukan dengan cara meletakkan aqua gelas plastik yang berisi larutan deterjen dipermukaan tanah yang telah dilubangi secara vertikal, setiap bedengan terdapat 2 buah pitfall trap sehingga total keseluruhan adalah 60 perangkap. Pemasangan pitfall trap dimulai dari jam 09.00 pagi sampai jam 09.00 keesokan harinya (24 jam). Pengambilan sampel dilakukan sebanyak 5 kali pada setiap bedeng. Pengamatan dilakukan mulai saat tanaman berumur 30, 35, 40, 45 dan 50 (fase vegetatif) dan saat tanaman berumur 55, 60, 65, 70, dan 75 hst (fase generatif) dengan interval waktu 5 hari.

\section{Pengumpulan sampel arthropoda}

Arthropoda yang sudah terperangkap dalam setiap pitfall trap disaring menggunakan saringan teh lalu dipindahkan ke dalam botol sampel yang telah berisi alkohol sebanyak $15 \mathrm{ml}$ 
kemudian diberi label pada botol sampel sesuai pengamatan. Pemberian alkohol pada botol sampel bertujuan untuk mengawetkan arthropoda dan agar mudah untuk mengidentifikasinya.

\section{Identifikasi arthropoda}

Semua Arthropoda permukaan tanah yang terperangkap dibawa ke Laboratorium Hama Tumbuhan untuk diidentifikasi sampai tingkat famili. Identifikasi serangga dilakukan dengan menggunakan mikroskop binokuler merek Yazumi XSZ-107BN dan metode Borror et al. (1996).

\section{Peubah yang diamati}

\section{Populasi arthropoda permukaan tanah}

Pengamatan meliputi identifikasi ordo, famili serta jumlah individu.

\section{Indeks keanekaragaman arthropoda permukaan tanah}

Menurut Maguran (2004), nilai indeks keanekaragaman berkisaran 1,5 - 3,5 jarang melebihi 4. Indeks keanekaragaman arthropoda permukaan tanah pada pertanaman cabai merah, cabai rawit dan tomat, dihitung dengan menggunakan rumus indeks keanekaragaman Shannon- Wiener:

$$
\mathrm{H}^{\prime}=-\sum_{i=1}^{s} p i(\operatorname{Ln} p i)
$$

Keterangan :

$$
\begin{aligned}
& \mathrm{H}^{\prime}=\text { Indeks keanekaragaman Shannon-Wiener } \\
& \mathrm{Pi}=\mathrm{ni} / \mathrm{N} \\
& \mathrm{ni}=\text { Jumlah individu setiap famili } \\
& \mathrm{N}=\text { Total keseluruhan individu setiap famili }
\end{aligned}
$$

\section{Indeks kelimpahan arthropoda permukaan tanah}

Nilai indeks kelimpahan (D) berkisar antara 0-1, tidak melebihi 1. Indeks kelimpahan arthropoda permukaan tanah pada pertanaman cabai merah, cabai rawit dan tomat dapat dihitung dengan menggunakan rumus indeks Simpson (Maguran, 2004):

$$
D=\sum_{i=1}^{n} \frac{(n i(n i-1)}{(\mathrm{N}(\mathrm{N}-1)}
$$

Keterangan :

D = Indeks Simpson

ni $=$ Jumlah individu setiap famili

$\mathrm{N}=$ Total keseluruhan individu setiap famili 


\section{HASIL DAN PEMBAHASAN}

\section{Populasi Arthropoda Permukaan Tanah}

Hasil identifikasi serta keanekaragaman arthropoda permukaan tanah pada tanaman famili solanaceae (cabai merah, cabai rawit dan tomat) dapat dilihat pada Tabel 1 berikut ini.

Tabel 1. Hasil identifikasi serta keanekaragaman arthropoda permukaan tanah pada tanaman cabai merah, cabai rawit dan tomat.

\begin{tabular}{|c|c|c|c|c|c|c|}
\hline \multirow{2}{*}{ Kelas } & \multirow{2}{*}{\multicolumn{2}{|c|}{ Ordo }} & Cabai merah & Cabai rawit & Tomat & \multirow{2}{*}{$\begin{array}{l}\text { Peran } \\
\text { Ekologis }\end{array}$} \\
\hline & & & Famili & Famili & Famili & \\
\hline Arachnida & \multicolumn{2}{|c|}{ Araneae } & $\begin{array}{l}\text { Lycosidae } \\
\text { Eutichuridae } \\
\text { Thomisidae }\end{array}$ & $\begin{array}{l}\text { Lycosidae } \\
- \\
- \\
\end{array}$ & $\begin{array}{l}\text { Lycosidae } \\
- \\
- \\
\end{array}$ & $\begin{array}{l}\text { Predator } \\
\text { Predator } \\
\text { Predator } \\
\end{array}$ \\
\hline Chilopoda & \multicolumn{2}{|c|}{ Lithobiomorpha } & Lithobiidae & - & Lithobiidae & Predator \\
\hline \multirow[t]{2}{*}{ Diplopoda } & \multicolumn{2}{|c|}{ Polydesmida } & Paradoxosomatidae & Paradoxosomatidae & Paradoxosomatidae & Dekomposer \\
\hline & \multicolumn{2}{|c|}{ Spirobolida } & Trigoniulidae & Trigoniulidae & Trigoniulidae & Detrivor \\
\hline \multirow[t]{9}{*}{ Insekta } & \multicolumn{2}{|c|}{ Coleoptera } & $\begin{array}{l}\text { Carabidae } \\
\text { Staphylinidae } \\
\text { Anthicidae } \\
\text { Aderidae } \\
\end{array}$ & $\begin{array}{l}\text { Carabidae } \\
- \\
\text { Anthicidae } \\
- \\
- \\
\end{array}$ & $\begin{array}{l}\text { Carabidae } \\
- \\
- \\
- \\
\text { Boridae } \\
\end{array}$ & $\begin{array}{l}\text { Predator } \\
\text { Predator } \\
\text { Dekomposer } \\
\text { Predator } \\
\text { Dekomposer } \\
\end{array}$ \\
\hline & \multicolumn{2}{|c|}{ Orthoptera } & $\begin{array}{l}\text { Gryllidae } \\
\text { Acrididae } \\
\text { Gryllotalpidae }\end{array}$ & $\begin{array}{l}\text { Gryllidae } \\
- \\
- \\
\end{array}$ & $\begin{array}{l}\text { Gryllidae } \\
\text { Acrididae } \\
-\end{array}$ & $\begin{array}{l}\text { Fitofag } \\
\text { Fitofag } \\
\text { Fitofag }\end{array}$ \\
\hline & \multicolumn{2}{|c|}{ Hymenoptera } & Formicidae & Formicidae & Formicidae & Predator \\
\hline & \multicolumn{2}{|c|}{ Dermaptera } & - & $\begin{array}{l}\text { Anisolabididae } \\
\text { - }\end{array}$ & $\begin{array}{l}\text { Anisolabididae } \\
\text { Forficulidae }\end{array}$ & $\begin{array}{l}\text { Predator } \\
\text { Predator }\end{array}$ \\
\hline & \multicolumn{2}{|c|}{ Hemiptera } & $\begin{array}{l}- \\
-\end{array}$ & $\begin{array}{c}\text { Cydnidae } \\
-\end{array}$ & $\begin{array}{l} \\
\text { Psyllidae }\end{array}$ & $\begin{array}{l}\text { Fitofag } \\
\text { Fitofag }\end{array}$ \\
\hline & \multicolumn{2}{|c|}{ Thysanoptera } & Thripidae & Thripidae & Thripidae & Fitofag \\
\hline & \multicolumn{2}{|c|}{ Blattodea } & - & - & Ectobiidae & Detrivor \\
\hline & \multirow{2}{*}{ Total } & Famili & 15 & 10 & 14 & \\
\hline & & Individu & 546 & 599 & 399 & \\
\hline
\end{tabular}

Berdasarkan Tabel 1 di atas dapat dilihat bahwa, pada pertanaman cabai merah terdapat 8 ordo arthropoda permukaan tanah (Araneae, Coleoptera, Hymenoptera, Lithobiomorpha, Orthoptera, Polydesmida, Spirobolida dan Thysanoptera) dan 15 famili dengan total 546 individu. Pada cabai rawit terdapat 9 ordo arthropoda permukaan tanah (Araneae, Coleoptera, Dermaptera, Hemiptera, Hymenoptera, Orthoptera, Polydesmida, Spirobolida dan Thysanoptera) dan 10 famili dengan total 599 individu dan pada tomat terdapat 11 ordo arthropoda permukaan tanah (Araneae, Blattodea, Coleoptera, Dermaptera, Hemiptera, Hymenoptera, Lithobiomorpha, Orthoptera, Polydesmida, Spirobolida dan Thysanoptera) dan 14 famili dengan total 399 individu.

Hasil pengamatan menunjukkan bahwa serangga ordo Hymenoptera dari famili Formicidae terdapat pada ketiga komoditi, pada tanaman cabai merah terdapat 164 individu, cabai rawit 322 individu dan tomat 112 individu. Selanjutnya urutan terbanyak kedua yaitu ordo Polydesmida famili Paradoxosomatidae terdapat di ketiga lahan penelitian, pada tanaman cabai 
merah yaitu 153 individu, cabai rawit 167 individu dan tomat 169 individu. Kemudian ordo terbanyak individu urutan ketiga yaitu ordo Orthoptera famili Gryllidae pada tanaman cabai merah terdapat 70 individu, cabai rawit 52 individu dan tomat 73 individu, sedangkan famili Acrididae yang didapatkan pada tanaman cabai merah dan tomat yaitu masing-masing 2 individu tetapi tidak ditemukan pada tanaman cabai rawit, kemudian famili Gryllotalpidae hanya terdapat pada tanaman cabai merah 1 individu sedangkan pada tanaman cabai rawit dan tomat tidak ditemukan famili tersebut.

Berdasarkan hasil identifikasi, famili Ectobiidae ordo Blattodea hanya terdapat pada tanaman tomat yaitu 1 individu, sedangkan pada cabai merah dan cabai rawit tidak ditemukan serangga dari ordo tersebut. Rendahnya serangga dari ordo Blattodea ada kaitan dengan faktor lingkungan salah satunya yaitu kelembaban tanah yang tinggi sehingga menyebabkan telur dari famili Ectobiidae yang berada di dalam tanah mengalami pembusukan dan gagal menetas. Basna et al. (2017) menyatakan bahwa ordo Blattodea yang didapatkan pada habitat perkebunan hanya terdapat satu famili yaitu Ectobiidae, rendahnya ordo ini berkaitan dengan kondisi lingkungan yang tidak mendukung dan ketersediaan makanan seperti bahan organik yang sedikit. Selanjutnya Nurmianti et al. (2015) menambahkan bahwa, ordo Blattodea yang ditemukan pada lahan padi sasak jalan hanya terdapat satu famili yaitu Ectobiidae.

\section{Indeks Keanekaragaman (H') Famili Arthropoda Permukaan Tanah pada Tanaman Cabai Merah, Cabai Rawit dan Tomat}

Indeks keanekaragaman merupakan suatu gambaran untuk menentukan tingkat keanekaragaman arthropoda permukaan tanah di lokasi penelitian. Tinggi rendahnya indeks keanekaragaman suatu spesies, tergantung pada banyaknya jumlah jenis dan individu masingmasing jenis. Menurut Maguran (2004), nilai indeks keanekaragaman berkisaran 1,5-3,5 dan jarang melebihi 4. Berdasarkan hasil analisis keanekaragaman arthropoda permukaan tanah (H') bahwa, pada ketiga jenis solanaceae (cabai merah, cabai rawit, dan tomat) menunjukkan adanya perbedaan nilai indeks pada masing-masing komoditi meski tidak terdapat perbedaan dalam kategorinya. Untuk lebih jelas berikut ini disajikan Tabel 2 nilai indeks keanekaragaman arthropoda permukaan tanah pada tanaman famili Solanaceae.

Tabel 2. Indeks keanekaragaman arthropoda permukaan tanah pada tanaman cabai merah, cabai rawit dan tomat.

\begin{tabular}{lcc}
\hline Tanaman & $\begin{array}{c}\text { Indeks keanekaragaman } \\
\left(\mathrm{H}^{\prime}\right)\end{array}$ & Kategori (H') \\
\hline Cabai Merah & 1,64 & Sedang \\
Cabai Rawit & 1,27 & Sedang \\
Tomat & 1,32 & Sedang \\
\hline
\end{tabular}

Pada Tabel 2 dapat dilihat bahwa indeks keanekaragaman arthropoda permukaan tanah berbeda antar komoditi berkisar 1,27-1,64, namun masih termasuk kedalam satu kategori yaitu sedang. Penanaman tanaman secara monokultur dalam satu famili pada suatu agroekosistem mengakibatkan lingkungan tingkat keanekaragamannya tidak jauh berbeda, sehingga memiliki nilai indeks keanekaragaman arthropoda permukaan tanah yang hampir sama termasuk katagori sedang. Pola penanaman secara monokultur indeks keanekaragaman sedang, karena pada saat penelitian berlangsung curah hujan tinggi sehingga berpengaruh terhadap kehadiran jenis serangga permukaan tanah dilahan tersebut. Danti et al. (2018) menyatakan bahwa, indeks keanekaragaman arthropoda pada lahan monokultur tomat didapatkan sebesar 1,01 dengan 16 
famili dibandingkan pola tanam tomat secara polikultur sebesar 1,16 dengan 22 famili, hal ini dikarenakan penanaman secara polikultur memiliki indeks keanekaragaman yang lebih tinggi dan memiliki komposisi hama dan musuh alami yang lebih seimbang dibandingkan dengan penanaman secara monokultur.

\section{Indeks Kelimpahan Arthropoda Permukaan Tanah pada Tanaman Cabai Merah, Cabai Rawit dan Tomat}

Indeks kelimpahan arthropoda permukaan tanah merupakan jumlah arthropoda permukaan tanah atau banyaknya individu pada suatu lahan tertentu dalam suatu ekosistem. Nilai indeks kelimpahan berkisar antara 0-1, tidak melebihi 1 (Maguran, 2004). Berdasarkan hasil analisis indeks kelimpahan arthropoda permukaan tanah (D) pada penelitian ini tergolong rendah pada ketiga komoditi (cabai merah, cabai rawit, dan tomat). Untuk lebih jelas berikut ini disajikan Tabel 3 nilai indeks kelimpahan arthropoda permukaan tanah pada tanaman famili Solanaceae.

Tabel 3. Indeks kelimpahan arthropoda permukaan tanah pada tanaman cabai merah, cabai rawit dan tomat.

\begin{tabular}{cc}
\hline Tanaman & Indeks Kelimpahan \\
\hline Cabai Merah & 0,23 \\
Cabai Rawit & 0,38 \\
Tomat & 0,29 \\
\hline
\end{tabular}

Pada Tabel 3 di atas terlihat bahwa nilai indeks kelimpahan arthropoda permukaan tanah pada ketiga komoditi ini tergolong rendah, hal ini dipengaruhi oleh sumber makanan untuk melangsungkan hidupnya dan kondisi lingkungan serta penggunaan mulsa plastik di lahan penelitian, sehingga menyebabkan kehadiran arthropoda pada lahan penelitian tidak melimpah serta dapat menghambat perkembangbiakan arthropoda yang habitatnya didalam tanah. Indahwati et al. (2012) menyatakan bahwa, arthropoda akan melimpah jika kondisi lingkungannya mendukung seperti suplai makanan, kandungan oksigen dan adanya tempat berlindung dari gangguan maupun predator. Yatno et al. (2013) menambahkan bahwa, tinggi rendahnya populasi arthropoda pada suatu lahan erat hubungannya dengan ketersediaan sumber makanan serta faktor iklim mikro pada suatu lahan. Selanjutnya Agustinawati et al. (2016) menyatakan bahwa, salah satu faktor yang menyebabkan tinggi rendahnya populasi arthropoda permukaan tanah yaitu penggunaan mulsa serta adanya aplikasi pestisida.

\section{KESIMPULAN DAN SARAN}

\section{Kesimpulan}

Hasil penelitian menunjukkan bahwa, nilai keanekaragaman arthropoda permukaan tanah yang tertinggi diperoleh pada tanaman cabai merah yaitu 1,64 dibandingkan dengan cabai rawit 1, 27 dan tomat 1,32. Nilai indeks kelimpahan yang tertinggi terdapat pada cabai rawit yaitu 0,38 , sedangkan terendah pada tanaman cabai merah 0,23 dan tomat 0,29. 


\section{DAFTAR PUSTAKA}

Agustinawati., M, H, Toana. and A, Wahid., 2016. Keanekaragaman arthropoda permukaan tanah pada pertanaman cabai (Capsicum annum L.) dengan sistem pertanaman yang berbeda di Kabupaten Sigi. Jurnal Agrotekbis, 4(1), pp.8-15.

Al-daikh, O, B, H., A, S, M, H, El-roby. and A, H, El-mabrouk., 2018. Efficiency of bio fertilizers and compost on soil arthropod diversity and species abundance in organic tomato field. Jurnal Applied Science Reports, 21(2), pp.56-62.

Arifta, Y., 2016. Pengaruh variasi jenis pupuk terhadap keanekaragaman dan dinamika populasi arthropoda permukaan tanah (epifauna) pada lahan pertanian tanaman tomat (Lycopersium esculantum). Jurnal Biologi, 5(4). Pp.86-97.

Basna, M., R, Koneria. and A, Papu., 2017. Distribusi dan diversitas serangga tanah di Taman Hutan Raya Gunung Tumpa Sulawesi Utara. Jurnal Mipa Unsrat, 6(1), pp.36-42.

Borror, D, J., C, A, Tripleron. and N, F, Jhonson., 1996. Pengenalan Pelajaran Serangga. Terjemahan oleh S. Partosoedjono. Edisi 6. Gadjah Mada University Press.

Bianchi, F, J, J, A., C, J, H, Booij. and T, Tscharntke., 2006. Sustainable pest regulation in agricultural landscapes: a review on landscape composition, biodiversity and natural pest control. Journal Proceedings of the Royal Society B: Biological Sciences, 273, pp.1715-1727.

Danti, H, R., Y, Fitriana., A, M, Hariri. and Purnomo., 2018. Keanekaragaman arthropoda pada pertanaman tomat dengan sistem pertanaman berbeda di Kabupaten Tanggamus, Lampung. Jurnal Agrotek Tropika, 6(3), pp.139-145.

Indahwati, R., H, Budi. and I, Munifatul., 2012. Keanekaragaman arthropoda tanah di lahan apel Desa Tulungrejo Kecamatan Bumiaji Kota Batu. Prosiding Seminar Nasional Pengelolaan Sumberdaya Alam dan Lingkungan. UNPID, pp.31-34.

Latoantja, A, S., Hasriyanti. and A, Anshary., 2013. Inventarisasi arthropoda pada permukaan tanah di pertanaman cabai (Capsicum annum L.). Jurnal Agrotekbis, 1(5), pp.406-412.

Magurran, A, E., 2004. Ecological Diversity and Its Measurement. Chapman and Hall. London.

Nurindah., 2006. Pengelolaan agroekosistem dalam pengendalian hama. Balai Penelitian Tanaman Tembakau dan Serat, 5(2), pp.78-85.

Nurmianti., N, Hariani. and Budiman., 2015. Diversitas serangga permukaan tanah pada lokasi budidaya padi sasak jalan di Loa Duri Kabupaten Kutai Kartanegara. Jurnal Bioprospek, 10(2), pp.37-42.

Normasari, R., 2012. Keragaman arthropoda pada lima habitat dengan vegetasi beragam. Jurnal Ilmiah Unklab, 16(1), pp.41-50.

Qiptiyah, M., 2014. Keanekaragaman arthropoda tanah di perkebunan teh PTPN XII Bantaran Blitar. Skripsi. Universitas Islam Negeri. Malang. 
Sembiring, A, K., 2020. Kelimpahan dan keragaman macrofauna di Taman Hutan Raya Sultan Syarif Hasyim. Jurnal Ilmiah Pertanian, 16(2), pp.100-107.

Yatno., F, Pasaru. and A, Wahid., 2013. Keanekaragam arthropoda pada pertanaman kakao (Theobroma cacao L.) di Kecamatan Palolo Kabupaten Sigi. Jurnal Agrotekbis, 1(5), pp.421-428.

Yasurruni, K., 2018. Kelimpahan dan keanekaragaman arthropoda permukaan tanah pada ekosistem pertanaman cabai rawit (Capsicum frutescens L.) di Kuripan Lombok Barat. Artikel penelitian. Fakultas Pertanian Universitas Mataram. Lombok. pp.1-13. 